\title{
Recent progress in electro-optic polymer for ultra-fast communication
}

\author{
Fateh Ullah ${ }^{1,2+}$, Niping Deng ${ }^{1,2+}$ and Feng Qiu ${ }^{1,2^{*}}$
}

\author{
* Correspondence: qiufeng@ \\ westlake.edu.cn \\ ${ }^{\dagger}$ Fateh Ullah and Deng Niping \\ contributed equally and should be \\ regarded as co-first author. \\ ${ }^{1}$ Key Laboratory of 3D Micro/Nano \\ Fabrication and Characterization of \\ Zhejiang Province, School of \\ Engineering, Westlake University, 18 \\ Shilongshan Road, Hangzhou \\ 310024, Zhejiang Province, China \\ ${ }^{2}$ Institute of Advanced Technology, \\ Westlake Institute for Advanced \\ Study, 18 Shilongshan Road, \\ Hangzhou 310024, Zhejiang \\ Province, China
}

\begin{abstract}
The rocketed development concerning electro-optic polymers fundamentally motivated by its pragmatic application in envisioning second-order nonlinear optics and waveguiding are cardinal. Modern synthetic strategies consigned an outstanding optical quality amorphous polymers with enhanced properties. Documented data revealed a huge progress in understanding their implementation, however challenges still exist regarding their temporal stabilities etc. This review delivers a brief investigation of nonlinear optical (NLO) polymer materials demonstrated over previous decades. Besides, their categorical explanation along with their structural architecting via engineering polymeric backbone or functionalization of the molecular entities have been reviewed. Correspondingly, their temporal and thermal stabilities accompanied by NLO characteristics features are also discussed.

Keywords: Electro-optic polymers, Electro-optic coefficient, Hyperpolarizabilities polymers, Chromophores
\end{abstract}

\section{Introduction}

Information industry has drastically changed the people's lives attributed to the emergence of new technologies, such as: 5G, optical computing, internet, sensing, artificial intelligence and all sort of multimedia/data/signal processing [1-3]. To support this change, the optoelectronic device industry encounters unprecedented challenges and as well as opportunities $[4,5]$. For high-speed communication, the obstacle is to transform electronic signals in to optical signals with rapid pace. Developing superior electro-optic devices fundamentally acquire integrant such as efficient electro-optic (EO) modulator, which encodes electrical signals into optical domain, allowing the transmission of hefty information bandwidth photons while isolating them of electrical interference. The electro-optical modulator is based on the optical signal modulation which is an indispensable device in optical communication. In order to meet the rapid conversion of electro-optical signals, the requirements of attaining electro-optical modulators are getting higher and higher. The explicit requirements are as follows: 1) Low drive voltage; 2) Low optical loss; 3) Low energy consumption; 4) High bandwidth, etc. $[6,7]$.

\section{SpringerOpen}

(c) The Author(s). 2021 Open Access This article is licensed under a Creative Commons Attribution 4.0 International License, which permits use, sharing, adaptation, distribution and reproduction in any medium or format, as long as you give appropriate credit to the original author(s) and the source, provide a link to the Creative Commons licence, and indicate if changes were made. The images or other third party material in this article are included in the article's Creative Commons licence, unless indicated otherwise in a credit line to the material. If material is not included in the article's Creative Commons licence and your intended use is not permitted by statutory regulation or exceeds the permitted use, you will need to obtain permission directly from the copyright holder. To view a copy of this licence, visit http://creativecommons.org/licenses/by/4.0/. 
As researcher attributed more and more attentions towards modulator development the EO materials hold the essential part of the modulator $[8,9]$. However, the currently commercialized EO material is the lithium niobate crystal, while having an EO coefficient of merely $30 \mathrm{pm} / \mathrm{V}$ [10]. Therefore, the EO modulators processed with lithium niobate as the core material revealed complications such as high driving voltage and high energy consumption. Not only that, when the modulation frequency reaches the modulation limitation, the performance of EO modulator will drop rapidly. In order to solve the problems of high energy consumption and modulation limit, the organic EO materials have received an extensive attention from the scientific community due to their excellent performance.

Globally, the scientific community is indulged in developing novel EO organics, encountering prerequisites such as elevated nonlinear and quick response, outstanding optical transparency etc. [11-13]. While exploiting numerous material systems, the EO-based organics have been recognized as an auspicious system in accomplishing requisites desired for developing EO technologies. The EO organics are intrinsically advantageous over its counter inorganic EO crystals in the many aspects: 1) enormous Pockels coefficients ( $\mathrm{r}_{33}$ standards greater than $\left.1000 \mathrm{pm} / \mathrm{V}\right)$ [14]; 2) high-speed EO response (less than 10 femtoseconds); 3 ) comparatively smaller dielectric constants (3 to 4) in limited range around $250 \mathrm{GHz}(\mathrm{GHz})$, and minute dielectric loss tangent $\left(10^{-4}\right)$ [6]; 4) these organics display great compatibility in directing materials and substrates in systems; 5) complex architectures and arrays can be accomplished because of their extraordinary solution processability; 6) intrinsic radiation hardness and wide operation temperatures for space applications (Fig. 1) [15]. The EO organic materials with such appealing characteristics are cardinal in addressing EO devices undertaking a broad spectrum, while establishing adequate modulation via low energy and small-footprint devices [6].

In constructing EO polymers, modern synthetic tools have transformed molecular engineering approaches significantly by involving a couple of strategies: firstly, the NLObased organic materials rational designing followed by efficient architectural modification /functionalization, resulting in tuning the molecular (microscopic)

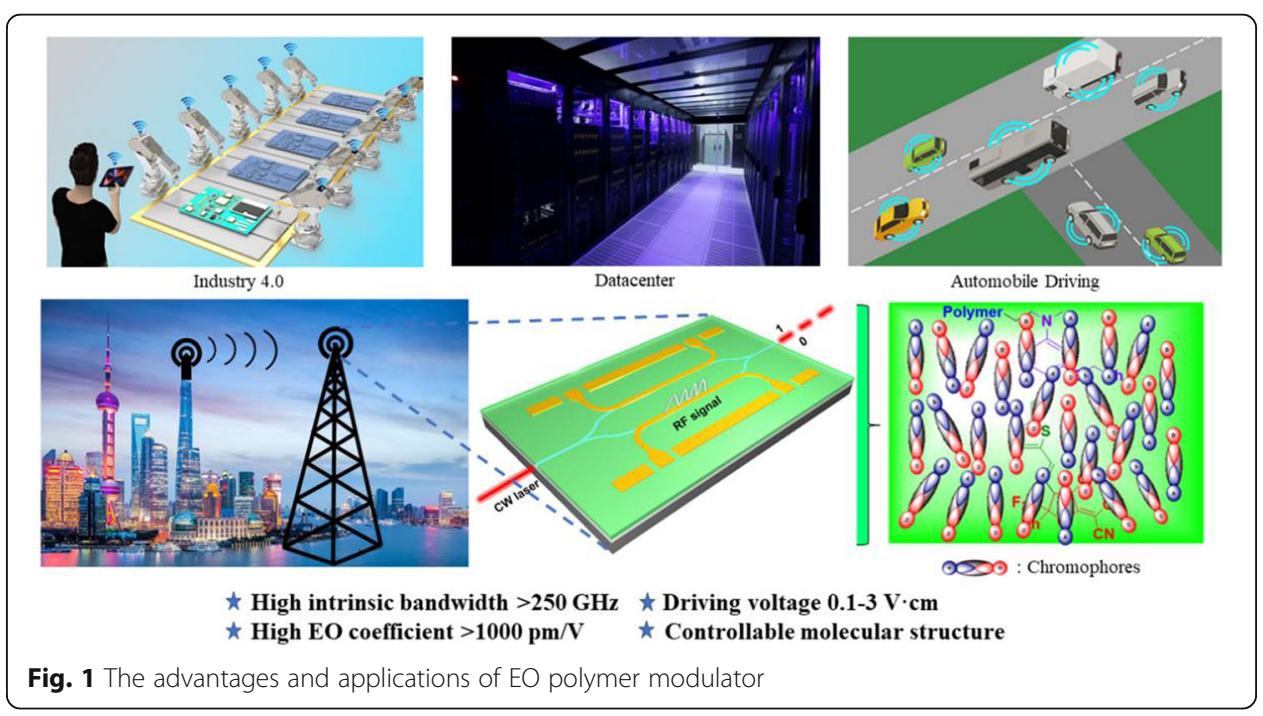


hyperpolarizabilities; secondly, constructing distinct molecular entities with enhanced hyperpolarizabilities of collective (macroscopic) assemblies [16-18]. Convincingly, engineering molecular organics via modern synthetic and sophisticated tools along with precision of device fabrication, devices with excellent performances can be achieved $[19,20]$. Additionally, confined state of NLO-based nanofabricated organics in a device disclose contrast and size dependent optical characteristics to that of conventional device architectures. Therefore, designing of novel NLO materials is cardinal to encounter the desired photonic features compatible with that of cutting-edge technologies. Undeniably, polymeric materials are the backbone of such tremendous technologies wing attributed to their attractive optical properties and ease of modification along with physical and chemical stabilities [21, 22]. Besides, characteristically such polymers are isotropic with amorphous and visible nature, providing fantastic optical standard with minimal optical propagation losses. Engineering novel photonic materials with versatile device architectures needs to be explored in realizing widespread commercial application. Abundant literatures regarding NLO organics have been documented, demonstrating large EO coefficients and enduring stabilities as well [23-25].

In this review we summarized the recent developments in organic second order NLO polymeric materials. Herein, we highlighted the most recent and significant developments in the dynamic arena of NLO organics along with their future perspectives. Addressing a brief introduction along with cardinal features required for designing of NLO materials in device application, followed by categorical classification and reviewing documented experimental results presented in well reputed journals and finally conclusion with future perspective is given.

\section{Functionalized EO polymers}

Common methodology designed for obtaining good optical quality, with large secondorder NLO susceptibility thin films is the functionalization of amorphous polymers with molecules exhibiting large first hyperpolarizability [26]. The stability of the material directly affects the lifetime of the EO device. For organic second-order NLO materials, stability includes not only the chemical stability of the core chromophore but also the stability in the subsequent conversion process, including thermal and long-term stability.

\section{Guest-host doped system}

The guest-host system is the straightforward approach in implementing materials on to the devices. The chromophores are simply dissolved followed by doping in to the polymer matrix functioning as guest. It is necessary to figure out an identical solvent for the individual constituents. The prepared solution can be directly implemented in the fabrication of thin films and is tailed by EO effect via electric field poling. Commercially accessible an optical quality polymeric materials including polyacrylates and polycarbonates and their derivatization in to amorphous polymers can function as host materials [27-30]. However, challenges still exist to optimize the nonlinear response of molecularly engineered NLO materials (chromophores and polymers). This system provides convenience in studying the process of chromophore poling and its corresponding orientation behavior while varying the chromophore loading densities. 
Selecting polymers functioning as host materials for chromophores, two factors are cardinal, the amorphous state and the glass transition temperature. A decrease in host polymer glass transition temperature $\left(T_{g}\right)$ will ultimately fluctuate the stability concerning molecular orientation, consequently reducing the EO movement. While, elevation of $T_{g}$ will influence the stability of the chromophore which might lead to its decomposition during poling process heating. An increase in $T_{g}$ of the host polymer is directly proportional to the chromophore loading density (become larger), thus, enhancing NLO materials EO activity. Besides, electric field-induced acentric order of chromophores in poled polymers declines with the passage of time. The temporal alignment stability of guest-host polymer system can potentially be enhanced via elevating poling temperatures (or $T_{g}$ of host polymeric materials) in comparison to the device operational temperatures. The polymeric materials having elevated $T_{g}$ performing as hosts in a composite with chromophores is advantageous (chromophores contributing as plasticizers eventually lowering the $T_{g}$ of the composite). However, employing elevatedtemperature poling process, highly efficient organics carrying extended $\pi$-conjugated backbones exposes itself to thermal decomposition, thus limiting the choice of high $T_{g}$ polymeric materials. Engineering EO polymers for potential applications, material parameters including optical absorption, scattering loss, and photochemical steadiness should be taken in consideration.

A number of polymers such as polyimide, poly-methyl methacrylate and amorphous polycarbonate (host-polymers) made it to extensively used polymeric materials in guest-host composites because of their enhanced temporal stabilities. A novel polymer material entitled as poly (NDI) (Fig. 2) with glass transition temperature of about $210^{\circ} \mathrm{C}$ was designed and synthesized [31]. The films carried an EO polymer involving $\mathrm{C} 1$ and $\mathrm{C} 2$ in the composite as guest chromophores. The experimental glass transition temperature of the polymer composite (after poling) was at $188^{\circ} \mathrm{C}$ with EO coefficient around $93 \mathrm{pm} / \mathrm{V}$, subsequently treated at $85^{\circ} \mathrm{C}$ for a duration $500 \mathrm{~h}$, the initial EO coefficient value was maintained at above $70 \%$. The host-guest composite system (with EO material) is the straightforward approach in implementing materials with highest quality and is most widely used in poling of polymeric materials. However, challenges still exist for practical applications such as, lack of true chemical bonding between the chromophore and its respective polymer unit, because of less thermal steadiness of
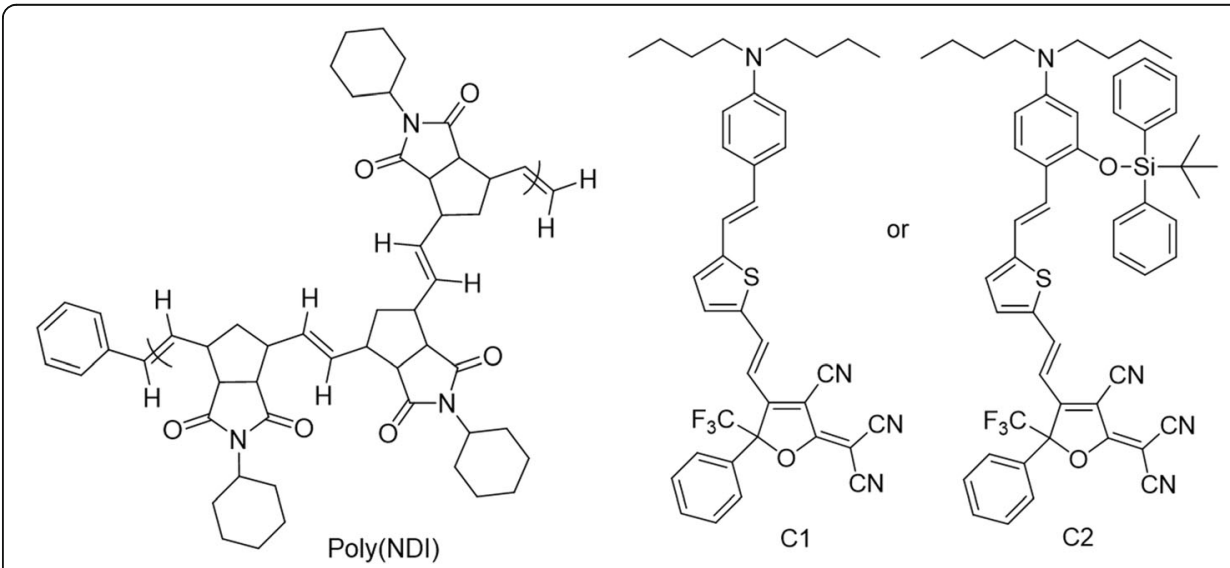

Fig. 2 Host-guest EO material poly(NDI)/C1 and C2 
chromophore an exposure to orientation relaxation ultimately reduces the EO activity, and lastly process of film formation process can lead to the phase separation. Considering aforementioned challenges, Hydrogen bonding was a new methodology to enhance the long-term stabilities of the host-guest system [32]. Researchers constructed HPB2 (composite contained a blend of PMMA-co-PHPM and P4VP) (Fig. 3) polymeric network connected through hydrogen bonding, the then fabricated EO thin-film composition contained $\mathrm{HPB} 2 / 20 \%$ DFCT $-1\left(T_{g}=150^{\circ} \mathrm{C}\right)$, longtermly stable while maintained low EO coefficient of merely $30 \mathrm{pm} / \mathrm{V}$ ). The authors tested the thermal stability of the composite by exposing the material to $85^{\circ} \mathrm{C}$ for a period of $250 \mathrm{~h}$, they revealed that $85 \%$ of the initial EO coefficient can be retained. In comparison to the values documented for amorphous polycarbonate (APC) material (retaining merely $75 \%$ of the initial EO coefficient of APC/10\% DFTC-1), this system ensured its potential for future application.

Such hydrogen bonded (guest-host composite) system is advantageous in a couple of ways: first, the loading density of the chromophores in EO film can regulate well in the presence of extensive hydrogen bonded networks; second, the diverse features of such bonding (dynamics, reversibility, and temperature) potentially enhances the EO material stabilities [16]. As the molecular motions are directly dependent on temperature, an increase in temperature ultimately enhances the molecular motions. But once the temperature approaches the poling temperature, the three-dimensional arrangement engaging chromophores by means of hydrogen bonding vanishes. Now, hydrogen bond will no longer hold the free molecular moment present in chromophores when external voltage is applied. Subsequently, bringing down the temperature to ambient temperature (post poling process) will yet again permit hydrogen bonding in molecular organics, revealing three-dimensional network and eventually constraining chromophore moments, therefore, EO materials with enduring stabilities can be accomplished. Despite of such attractive characteristics, a couple of disadvantages are accompanying this system, such as: solvent compatibilities and the dipole-dipole interactive forces present among chromophores cannot be effectively inhibited.

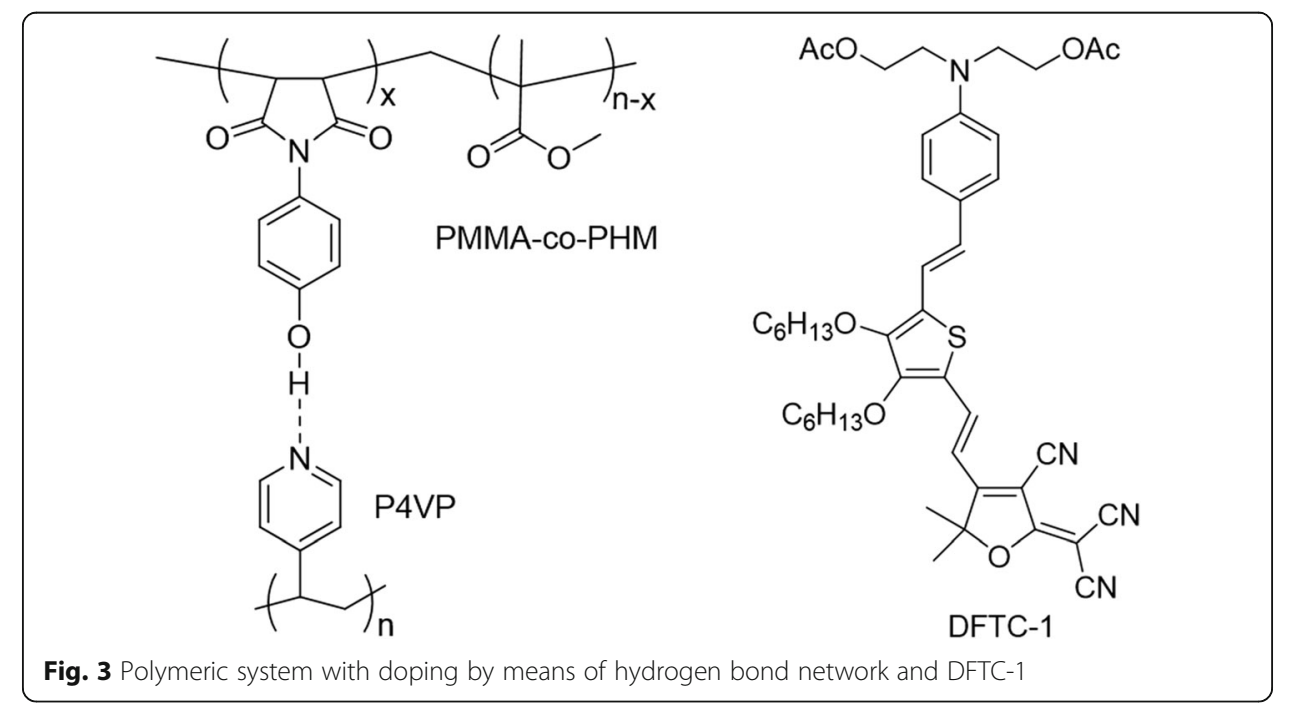




\section{Main-chain EO polymer}

Construction of main-chain polymer system involves the NLO-based organics (chromophores) as one of the monomer and is chemically bonded with respective monomer to form polymeric system. In such system, an increase in chromophore loading density is proportionally inhibiting the macro-phase separation, elsewise limiting chromophore relaxation within the polymer backbone. Therefore, most commonly engineered EO polymeric materials having main chain organics reveal sophisticated orientational stabilities. This system includes polymeric backbones constructed of Polyimide, polyurethane, polyarylether, and polyester etc. [33-37].

Earlier, polyimides being extensively exploited polymers in engineering main-chain polymeric backbones and they acknowledged preeminent glass transition temperatures [38-43]. Recent documentation described the temporally stable novel polymers indulging polyimide (P1) and polyurea (PU) along with second-order NLO based organics [44]. These polymers were connected with molecular entity entitled as 2,3-bis (4-aminophenyl)-5,6-dicyanopyrazine (BAPDCP) with measured first-order molecular hyperpolarizability of $123.5 \times 10^{-30} \mathrm{esu}$. Polymers P1and PU revealed the EO coefficient of 16.5 and $27.7 \mathrm{pm} / \mathrm{V}$ at $1064 \mathrm{~nm}$, correspondingly. Furthermore, polyimide based sample was placed for poling, presenting the onset temporal deterioration about $200^{\circ} \mathrm{C}$. Similarly, another successful investigation featured polyimides $(\Lambda$-shape PI) based mainchain system with carbazole constructed two dimensional organic (chromophore) and revealed high temporal stability [45]. The engineered 2D polymer displayed fantastic temporal stability at $350{ }^{\circ} \mathrm{C}$ with no substantial weight loss. The implemented coronapoling operated at $210{ }^{\circ} \mathrm{C}$ while exhibiting a EO coefficient value of $17.2 \mathrm{pm} / \mathrm{V}$. Additionally, the newly developed chromophore (carbazole based chromophore) in the 2D polymeric backbone showed more liability towards poling with respect to the electric field direction while conventional head to tail main-chain polymeric systems were lack of such liability of poling.

Classical literature reported novel EO polymers with polyimide structural backbone [36]. The researchers introduced a sequential self-repetitive strategic reaction which eventually lead to wholly aromatic polyamide architectures. The respective polymers PI1 and PI2 (Fig. 4) delivered an ideal $T_{g}$ figures of $196^{\circ} \mathrm{C}$ and $208^{\circ} \mathrm{C}$ respectively, while revealing poor EO coefficient of merely $25 \mathrm{pm} / \mathrm{V}$ (for PI2) retaining $92 \%$ of the initial EO activity. In 2013, new isolation functional groups were introduced for manufacturing polycarbonate-based (Fig. 5) EO materials [46]. Introducing direct polymerization technique between various chromophore (performing as monomer) and bisphenol as monomer, resulting in EO active polycarbonates. The glass transition temperature of then prepared polymers carrying different chromophore loading densities resonated between 130 and $170{ }^{\circ} \mathrm{C}$, while highest EO coefficients approached $75 \mathrm{pm} / \mathrm{V}$.

Recently, documentation regarding NLO polymers engineered with novel chromophores, facilitating the main-chain polymers synthetically and present good solution stabilities [33]. The new strategy implemented novel chromophore working as monomer bearing carboxylic functionalities at the terminal points, while the counter monomer contained benzene unit with ethyl side chains which are terminally functionalized with hydroxyl groups. The then synthesized polyester polymers (PE-1 PE-2) revealed fantastic thermal stabilities of $305^{\circ} \mathrm{C}$ and $223^{\circ} \mathrm{C}$ for PE-1 and PE-2 respectively. While, because of the structural resemblance and their corresponding molecular interactions, 


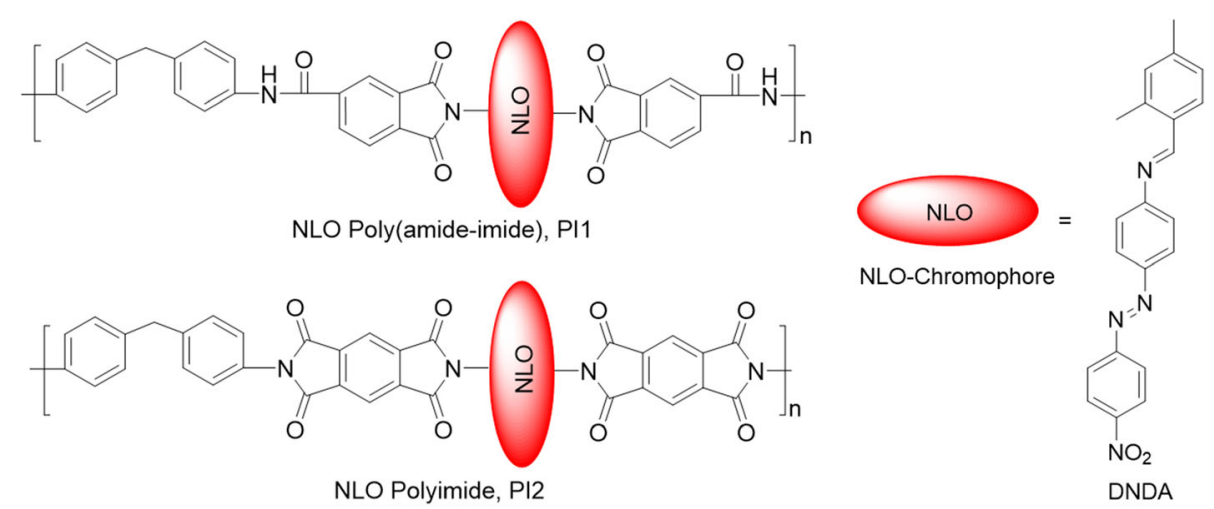

Fig. 4 Main-chain polymer structures involving polyimide

the $T_{g}$ analysis delivered almost identical values for PE-1 $\left(113^{\circ} \mathrm{C}\right)$ and PE-2 $\left(108^{\circ} \mathrm{C}\right)$. Moreover, employing corona-poling to these polymer films presented the EO coefficient values of $26.3 \mathrm{pm} / \mathrm{V}$ (PE-1) and $35.8 \mathrm{pm} / \mathrm{V}$ (PE-2) and insignificant decline occurred in the original value after being backed at $85^{\circ} \mathrm{C}$ for over hundreds of hours.

\section{Side-chain EO polymer}

Side-chain EO polymers can be accomplished by means of covalently anchored molecular dipolar organics (chromophores) functioning as side chain/substituent to the backbone of host polymer material. Construction of such polymer system is advantageous by means of uniform film deposition which in turn inhibits molecular crystallization along with phase separation as well. Besides, this system predominantly suppresses the relocation of chromophore and challenges governed by chromophore loading density for long term application. Moreover, side chain polymer system retain its degree of freedom which eventually can enhance the poling competency to that of host-guest system. Most commonly used polymers in this system includes, the Vinyl based NLO polymers (polystyrene and polymethyl methacrylate) and NLO polymeric materials having elevated $T_{g}$ such as, polyurethane, polyimide, polyamide, polyester, polyether, and polyquinoline [47-52]. Previously a substantial literature regarding various side-chain NLO polymer categories have been documented [53-63].

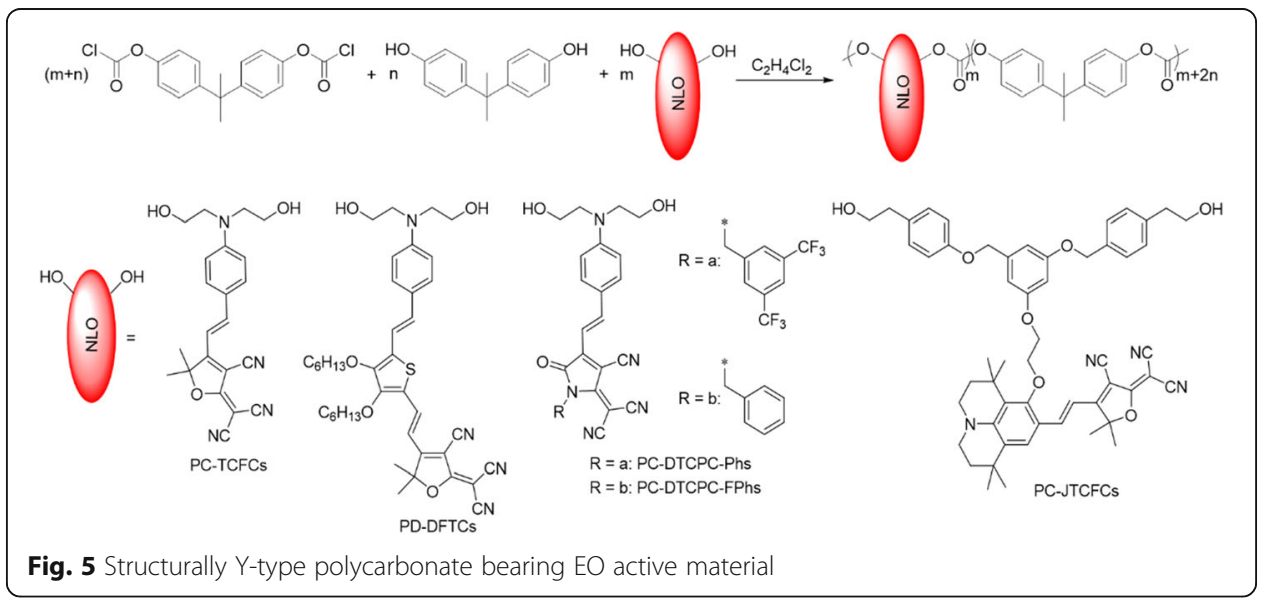


The targeted side-chain EO-active polymeric materials can be accomplished by a couple of methodologies i.e. direct polymerization and post-functionalization. Direct polymerization process involved, the synthesis of the respective chromophores functioning as monomers which are followed by copolymerization with their partner monomers. Synthetically, such polymerization generally involved the free radical and esterification reactions. While the post-functionalization methodology in accomplishing EO-active polymer materials involve the attachment of EO organics to the polymer backbone by means of a chemical reaction. The targeted post-functionalization can be realized through Catalyzed esterification, Mitsunobu etherification, the Diels-Alder addition reaction, the Huisgen reaction, the Kneovenagel condensation reaction, and the nucleophilic reaction of isocyanate with hydroxyl groups. The employment of polycarbonates, in particular the amorphous polycarbonate (APC) have been extensively utilized as host polymers for attachment of NLO chromophores because of their attractive feature, such as elevated $T_{g}$, decent film processability and respectable optical properties. In 2008, researchers documented a communication regarding NLO polymer the APC (Fig. 6a), utilizing carboxylic acid containing bisphenol performing as monomer followed by appropriate insertion of functionalized organics via esterification [64]. Their polymers bearing high chromophore loading density delivered elevated $T_{g}$ as high as $202{ }^{\circ} \mathrm{C}$, while the recorded EO coefficient for TCF-based chromophore was merely $38 \mathrm{pm} / \mathrm{V}$ (at $1300 \mathrm{~nm}$ ).

The glass transition temperatures of other similar polymeric entities such as polyamides and polyquinolines loaded with side-chain chromophores are also elegant approaching as high as $215^{\circ} \mathrm{C}$ which are beneficial in long term device stabilities. Earlier, a new synthetic strategy (Stile cross coupling polymerization) was implemented which carried chemically sensitive units [49]. This approach utilized monomers (NLO chromophores) with bromine atoms for coupling reactions of aromatic polyamides (Fig. 6b). The resulting polymers exhibited large $\mathrm{r}_{33}$ value of $35 \mathrm{pm} / \mathrm{V}$ at $1300 \mathrm{~nm}$ and maintained high temporal stability at $80^{\circ} \mathrm{C}$. Similarly, researchers employed an efficient synthetic procedure for side-chain NLO polyquinolines [50]. Their synthesis involved polycondensation of bis (ketomethylene) monomer with bis-(o-amino ketone) monomers (Fig.

(a)

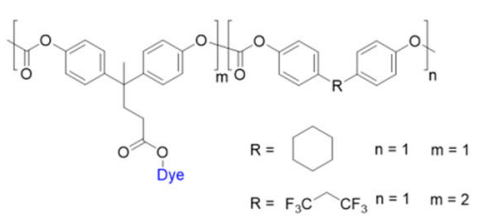

(b)

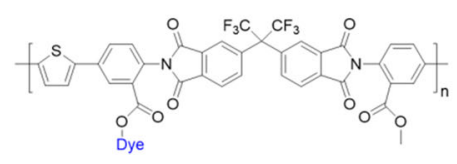

(c)

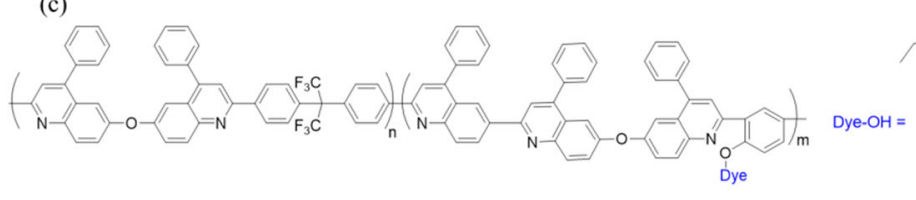

Fig. 6 Polymers with side-chain EO chromophores
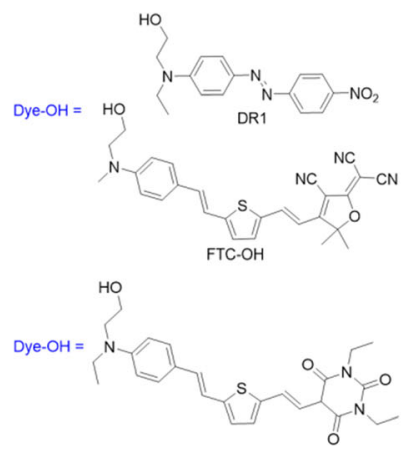

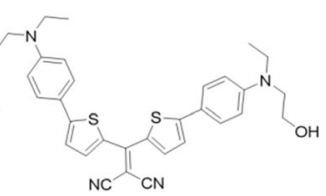


6c). Although, the EO coefficient of this polymer was low but they delivered temporal alignment stability at around $100{ }^{\circ} \mathrm{C}$. Moreover, their methodology proposed tremendous flexibility in selecting the polymeric backbone which is beneficial for tuning the opto-physical characteristics of such polymer materials. In 2017, scientists introduced novel EO polymer comprised of side-chain polyester connected to a chromophore with two comparatively elongated flexible chains (Fig. 7) which are terminally flanked with carboxyl functionalities ensuring mobility of the chromophores concerning host polymer matrix [65]. Three polymers GL-S-1, GL-S-2 and GL-S-3 were prepared which are having identical cores with different chromophore loading. The results confirmed that the glass transition temperatures of these polymers are around $110^{\circ} \mathrm{C}$, while the chromophore loading density was directly proportional to EO coefficient values (29.3 $\mathrm{pm} / \mathrm{V}$ for GL-S-1, $43.6 \mathrm{pm} / \mathrm{V}$ for GL-S-2 and $63.1 \mathrm{pm} / \mathrm{V}$ for GL-S-3).

Recently documented EO polymers (Fig. 8a) based on side-chain strategy, sequentially comprised of an adamantyl moiety (with desired loading densities) for enhancing thermal characteristics of the then synthesized polymers. Expectedly, progressive enhancement in loading density of adamantyl proportionally enhanced the $T_{g}$ of the respected polymers eventually approaching $194{ }^{\circ} \mathrm{C}$ (for EO194). Furthermore, the fabricated modulator involving Mach-Zehnder (MZ) interface modulator delivered fantastic thermal resistivity at elevated temperatures $\left(105^{\circ} \mathrm{C}\right)$ approximately up to $2000 \mathrm{~h}$ for polymer EO194 [66]. Same research group, optimized aforementioned polymer via molecular engineering which ultimately sharpened the polymeric backbone (Fig. 8b), modified nonlinearity and enhanced its $T_{g}$ [67]. Additionally, the researchers constructed silicon-polymer hybrid modulator which sustained an ultra-fast single-lane data rates approaching 200 gigabits/second. The authors claimed that the newly constructed ultrahigh speed SPH modulator exhibited resistance to high temperature up to $110^{\circ} \mathrm{C}$, while maintaining high-speed signal fidelity, and guaranteeing high EO activities.

\section{Cross-linked systems EO polymer}

The cross-linking strategy is currently occupying research hotspot and is advantageously providing better temporal and long term stabilities to the induced EO materials [22]. The NLO molecular organics bearing crosslinking units react by means of chemically attached units to the adjacent polymer backbones and governed a steady 3D polymer network which efficiently inhibit the chromophore relaxation

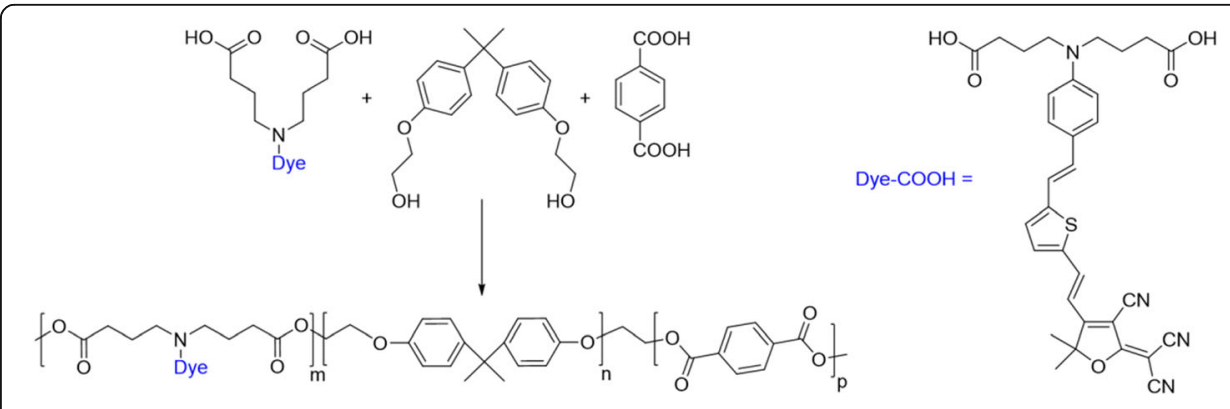

Fig. 7 Structure and synthesis of polymer GL-S1 
(a)

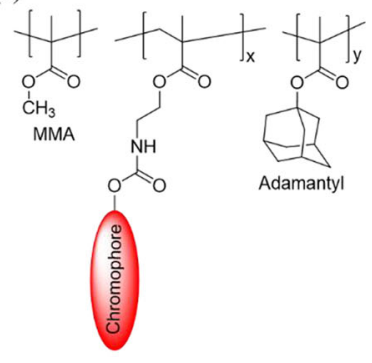

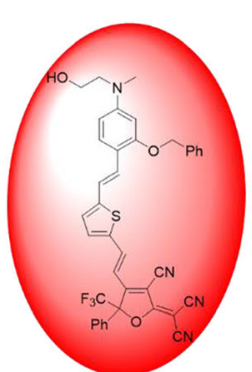

(b)

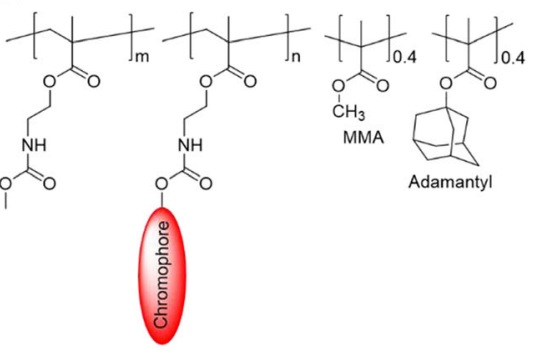

Fig. 8 a Chemical structure of the synthesized side-chain EO polymer $\mathbf{b}$ Modified chemical structure of the synthesized side-chain EO polymer

process along with effectively maintained EO characteristics. The cross-linking procedure should to be accomplished under well controlled environment of applied electric field, because the glass transition temperature of polymeric materials upsurges with applied heating or with enhanced illumination time. Since, this system effectively suppress chromophores relaxations while maintaining long term EO coefficient, the system must fulfill the following conditions: a) original structure of the respective chromophore should be retained during cross-linking operation, b) reaction timing is cardinal thus should be controlled (poling before crosslinking), c) the required temperature for the cross-linking reaction should be equivalent to the glass transition temperature, and d) the orientation momentum concerning chromophore must overwhelm the cross-linking speed.

Since, the NLO chromophores display strong absorbance in the short wavelength region, the photo-crosslinking methodologies deliver low efficiencies which could be attributed to photobleaching effect. Limited number of publications are documented which implemented the photo cross-linking systems. However, although one recent example introduced in situ photo cross-linking for engineering of poly (aryl ether ketone) and the functionalized chromophores were terminated with anthracene groups [68]. The authors claimed that their designed reaction strategy could be efficiently accomplished under mild condition and is highly productive for delivering enhanced poling efficiency and temporal stability. The data extracted from the polymers revealed the maximum EO coefficient of $28.5 \mathrm{pm} / \mathrm{V}$, while the depolarization temperature concerning dipole relaxation has been improved to $129^{\circ} \mathrm{C}$ (post crosslinking) displaying a $17^{\circ} \mathrm{C}$ increasement to the uncross-linked one. Besides, new methodologies were employed indulging thermal cross-linking system, and commonly used cross-linking as well as curative approaches (for polymer systems) which are given below. For constructing EO polymers via cross-linking strategies, it can be categorized in to three kinds of reactions.

\section{Cross-linking reaction indulging Diels-Alder (D-A) strategy}

A competent lattice-hardening technique exploiting the [4+2] D-A cycloaddition reaction $[3,69,70]$. This procedure entirely reverses the conventional applied thermal processing procedures regarding cross-linking and is significantly advantageous 
over the rest of NLO thermosets. The documented sequential cross-linked polymers utilizing D-A addition reaction, eventually obtained cross-linked EO polymers with elevated EO coefficient and enduring stabilities as well [8]. The authors constructed their molecular adducts by introducing the acrylate-functionalized dendritic NLO organics, while anthracene unit (Fig. 9) was introduced to the polymer backbones (P1 and P2) functioning as diene for D-A reaction. Subsequently, poling and cross-linking rewarded molecularly engineered polymers revealed highest EO coefficient of $126 \mathrm{pm} / \mathrm{V}$. The resultant polymers retained $88 \%$ of their original EO coefficient even after being exposed to heating at $150^{\circ} \mathrm{C}$. Furthermore, they increased the applied temperature up to $200{ }^{\circ} \mathrm{C}$ for a short period of $30 \mathrm{~min}$ and the material preserved its initial EO coefficient at $80 \%$. Such facile synthetic routes along with elevated temporal stabilities and high EO activities promotes this system towards promising device applications.

In 2012, researchers investigated the synthesis of polyacrylates with enhanced solubilities and various NLO organics [71]. Their D-A engineered cross-linked EO material included side-chain EO polyester bearing furan as diene for the respective reaction, while bismaleimide (BMI) (Fig. 10) as the cross-linkable moiety. The chromophore FTC-wl was the selected chromophore along with polymer sPAR and varied chromophore loading densities were produced. Their results revealed maximum EO activity of $124 \mathrm{pm} / \mathrm{V}$ anticipated for doped (FTC-wl) sPAR-CTCP system while keeping high chromophore density. Exploiting the maleimide-type chromophores to mild synthetic conditions, versatile but quantitative and avoiding catalytic impurities, governed polymers PM-1a, PM-1b, PM-2, and PM-3 by D-A post functionalization methodology. The resulted polymers displayed elevated dielectric strength, outstanding optical value with respectable processability, and were consistent with poling behaviors. The chromophore in polymers PM-1a and PM-1b is anchored to the central amide unit, while the polymers entitled as PM-1b, PM-2, and PM-3 are loaded with $20 \mathrm{wt} \%$ of the chromophore concentration. The poled film of polymer PM-2 revealed the best $\mathrm{r}_{33}$-value of around $60 \mathrm{pm} / \mathrm{V}$, while the polymer PM-1b delivered almost half $r_{33}(30 \mathrm{pm} / \mathrm{V})$ value to the former one. The polymer PM-3 film presented a comparatively decent $r_{33}$-value of $57 \mathrm{pm} / \mathrm{V}$. These respective outcomes were achieved because of the existence of dendritic entities, which eventually enhanced the poling efficiency of the polymers [72].

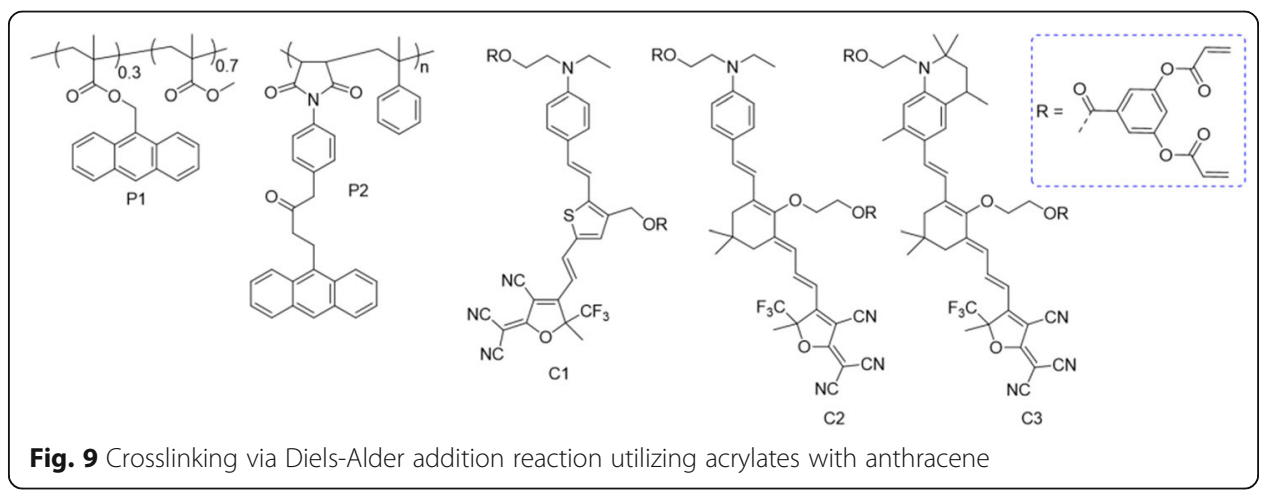




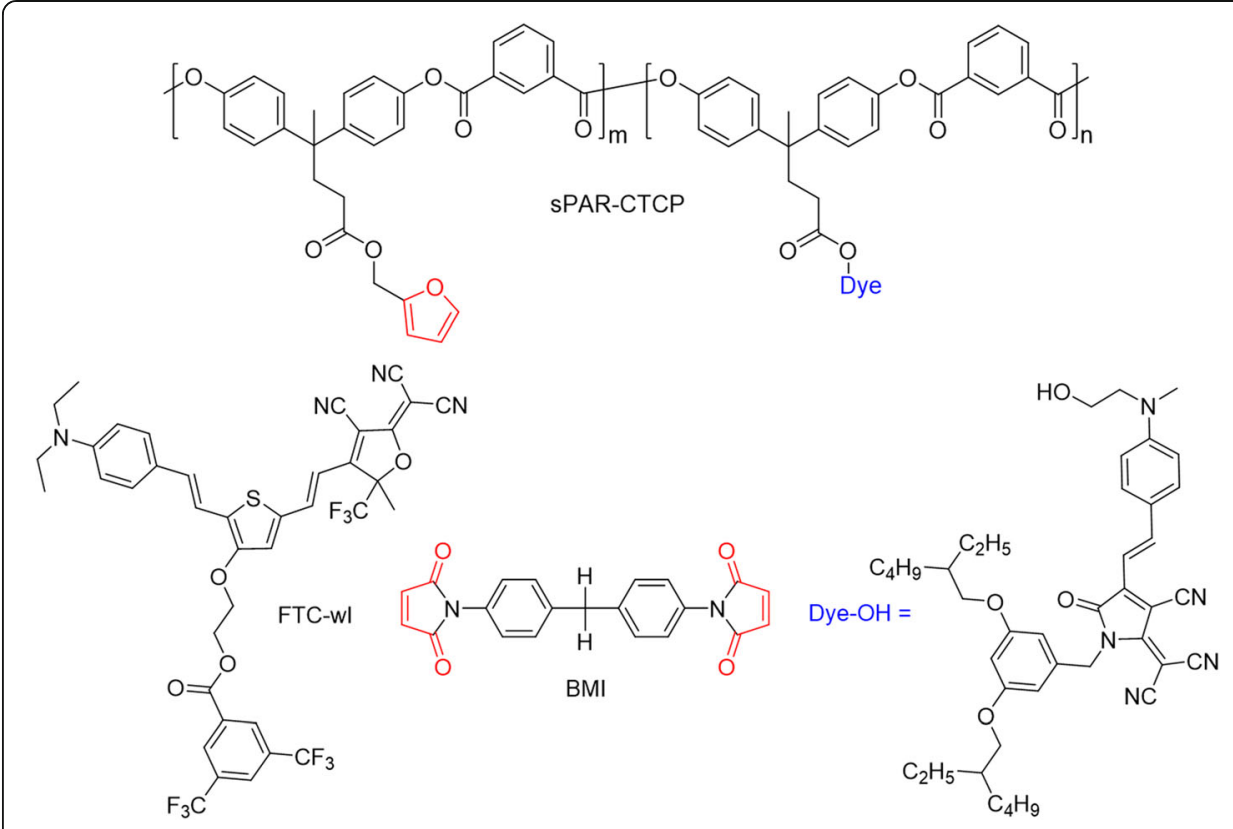

Fig. $10 \mathrm{EO}$ polyester system based on Diels-Alder reaction

\section{Cross-linking reaction indulging Huisgen strategies}

The Huisgen cross-linking reaction operates via click reaction, delivering efficient conversion of reactants, providing good selectivity and can be performed under mild conditions. Once the poling and cross-linking process is complete, the EO polymeric material with enhanced stabilities can be attained in comparison to non-cross-linked systems. Researchers employed this efficient protocol in the preparation of novel EO polymers based on azide-alkyne 1,3-dipolar cycloaddition [73]. They connected the polymer AJP12 (Fig. 11) bearing an azide substituent with chromophores (EOD1 and EOD2) having different alkynyl groups via in-situ cross-linking reaction. The author also utilized polar media for architectural control and the results revealed that cross-linking could potentially be facilitated in polar media. Furthermore, their poled polymers exhibited enhanced EO activities (up to $147 \mathrm{pm} / \mathrm{V}$ ) along with outstanding long-term alignment stability, and retained 93\% EO coefficient (of initial figure) at temperature of $85^{\circ} \mathrm{C}$ over a period of $500 \mathrm{~h}$. Similarly, a research team engineered EO active polymers, introducing chromophores which displayed compatibility towards free radical polymerization [74]. Their co-polymers strategy involved CPO chromophores, ethynyl and azido functional units, exhibited considerable EO coefficients approaching $41 \mathrm{pm} / \mathrm{V}$. Furthermore, such cross-linking strategy can potentially improve polymeric stability bearing optically active chromophores.

\section{Cross-linking reaction indulging hydroxyl and isocyanate groups}

In order to increase the extent of interaction involving polymeric backbone and their respective chromophores by means of true chemical bonding, another cross-linking approach towards EO polymer is to react hydroxyl and isocyanate. In 2012, the experts synthesized cross-linkable co-polymers with varied loading of chromophores [75]. Their synthetic route 


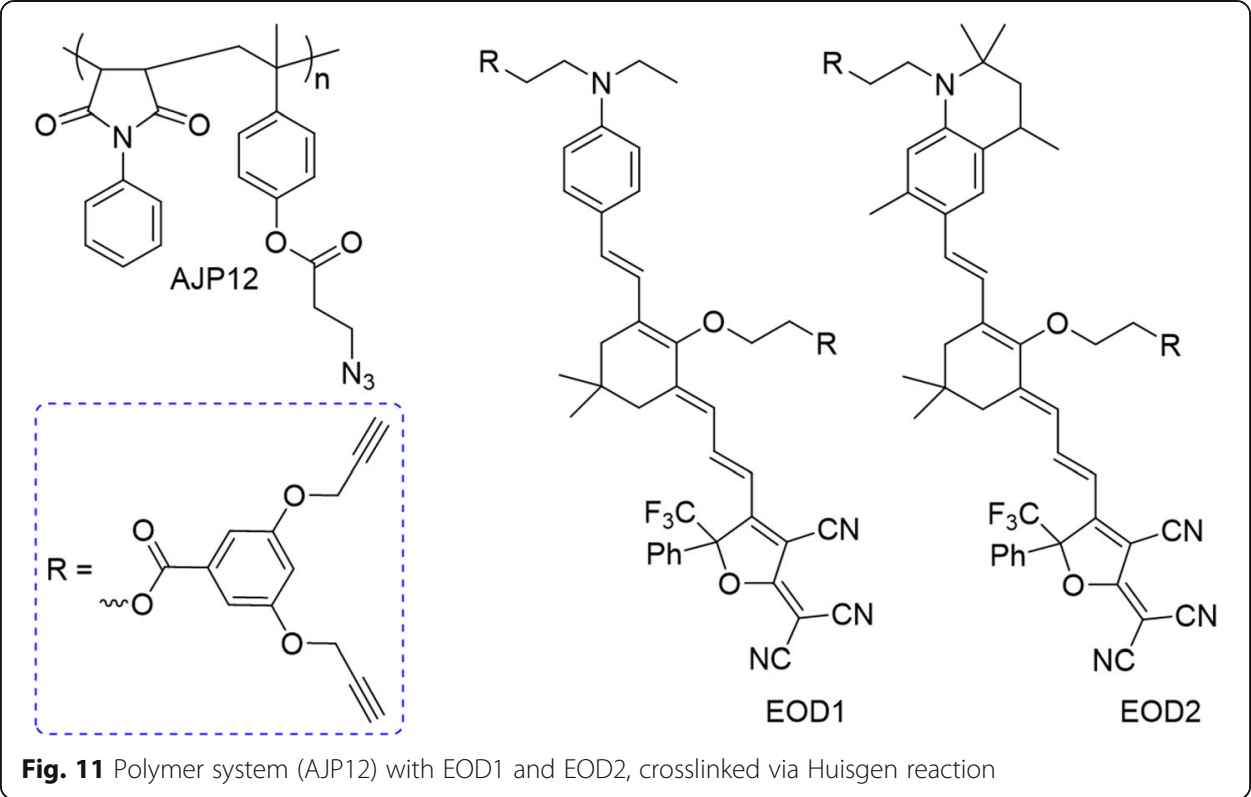

presented PMMA based copolymer system which has a hydroxyl functional unit (Fig. 12) while free radical polymerization was involved. Followed by solution preparation for spin coating, they added a cross-linkable molecular organic bearing a couple of isocyanate functional entities. Once the spin coating was over, it was followed by simultaneous termination of poling and cross-linking procedures. Owing to the reactive nature of hydroxyl and isocyanate groups, the cross-linking methodology could be accomplished in limited time at under mild reaction temperature $\left(140^{\circ} \mathrm{C}\right)$. Besides, through this technique, the functional chromophore loading densities and their respective compatibilities can also be amended. Additionally, their results provided an EO activity of $45.5 \mathrm{pm} / \mathrm{V}$ with retained $83 \%$ of the original EO coefficient at $80^{\circ} \mathrm{C}$ for $450 \mathrm{~h}$. In attaining tremendously rigid and enhanced cross-linked system, chromophores with elevated $\mu \beta$ standards are mandatory. Researchers introduced derivatization based on isophorone-based phenyltetraene chromophore (represented as CLD-5). For enhancing solubility and processibility, the $\pi$-conjugated bridge was substituted with hexyl chains, while dihydroxy functionalities were implemented for various crosslinking polyurethane systems. The EO polymer CLD-5/PPIF/BPDM polyurethane delivered higher EO coefficient of $41 \mathrm{pm} / \mathrm{V}$ and lower optical loss $\left(2.56 \mathrm{~dB} \mathrm{~cm}^{-1}\right)$ at $1300 \mathrm{~nm}$. The polymer revealed higher stability of $133^{\circ} \mathrm{C}$ indicating that excessive cross-linking deteriorates electric poling of long chromophores in a cross-linked polymer thin film [76].

\section{Conclusions and perspective}

We summarized the recent developments in EO polymers and are discussed categorically. All EO polymers loaded with chromophores, which are composed of an electron donor, a conjugate $\pi$-bridge and an electron acceptor. Since, individual chromophores have different first order hyperpolarizabilities, the one possessing higher first hyperpolarizability is more conducive and beneficial in obtaining macroscopic electro-optical properties. Besides, other key factors encompasses the polarization, physical and chemical stabilities of the EO material, and the cost-effective synthesis with reproducibility, 


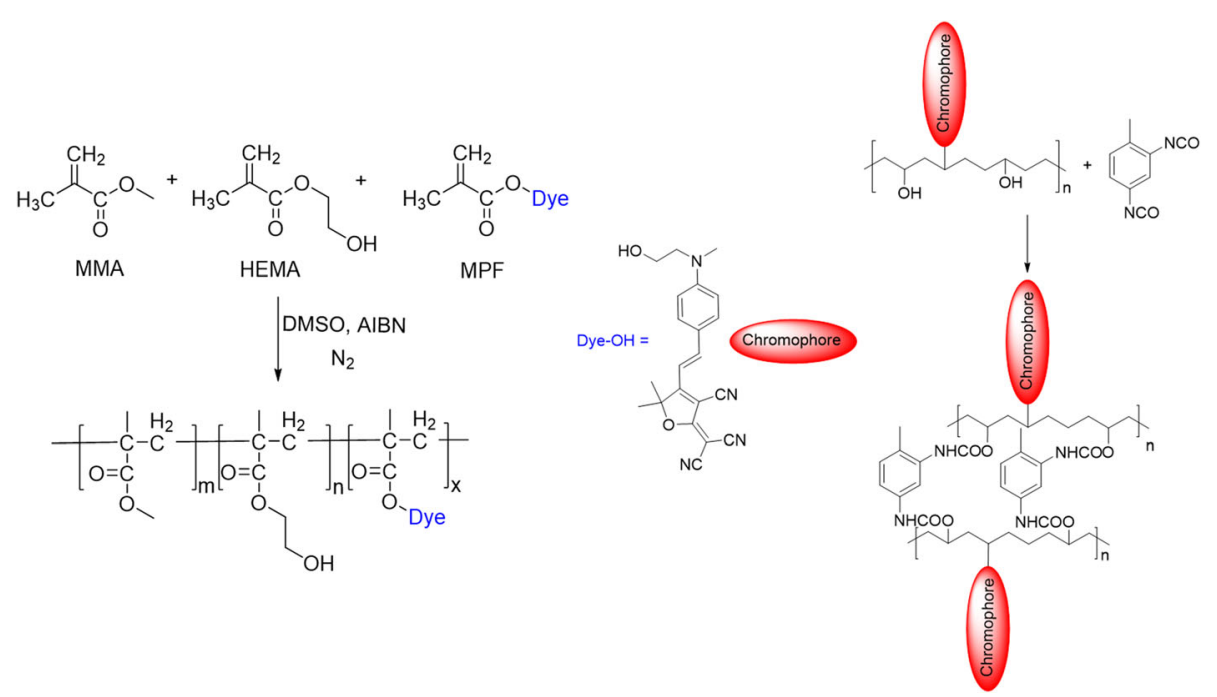

Fig. 12 Polymeric cross-linking system involving hydroxyl with isocyanate

etc. The development of electro-optic polymers has mainly gone through the following stages: 1 . Host-guest system; 2 . Side chain type polymer; 3 . Main chain type polymer; 4. Cross-linked type polymer. Some of the EO polymer parameters mentioned in the article can be seen in Table 1.

A number of documentation exploited the host-guest systems because of the ease of synthetic reproducibility and solving the polarization issue governed from the electrostatic interaction between the chromophores. However, such system appear with flaws

Table 1 The measured parameters of the entitled polymers

\begin{tabular}{|c|c|c|c|c|}
\hline NLO Polymer & $T_{g}\left({ }^{\circ} \mathrm{C}\right)$ & $T_{d}\left({ }^{\circ} \mathrm{C}\right)$ & $r_{33}(p m / V)$ & Reference \\
\hline P2 & 133 & 250 & 45.5 & [75] \\
\hline AJP12 & 150 & 204 & 147 & [73] \\
\hline PCC5 & 98 & 242 & 41 & [74] \\
\hline sPAR-CTCP & 122 & 253 & 124 & [71] \\
\hline P2 & 215 & 270 & 126 & [8] \\
\hline P5 & 91 & 276 & 28.5 & {$[68]$} \\
\hline EO194 & 194 & 105 & N/A & {$[66]$} \\
\hline N/A & 172 & 110 & N/A & [67] \\
\hline GL-S-3 & 113 & 239 & 63.1 & {$[65]$} \\
\hline P2 & 170 & 245 & 35 & [49] \\
\hline PC-AF-FTC & 174 & 303 & 38 & [64] \\
\hline PE-2 & 108 & 223 & 35.8 & [33] \\
\hline PC-DFTC-3 & 124 & 250 & 75 & {$[46]$} \\
\hline $\mathrm{PI} 2$ & 208 & 377 & 25 & [36] \\
\hline ^-shape PI & - & 350 & 17.2 & [45] \\
\hline PU & 248.7 & 285 & 27.7 & [44] \\
\hline Poly(NDI) & 210 & N/A & 93 & [31] \\
\hline
\end{tabular}

$T_{g}$ glass transition temperature, $T_{d}$ decomposition temperature determined at $5 \%$ weight loss

a. Polymer names described by the respective articles

b. $T g$ values given for the polymer with highest $r_{33}$ value

c. $T d$ values given for the polymer with highest $r_{33}$ value 
such as isolation of chromophores (not attached to the polymer chain) resulting poor stabilities, and compatibility of the host polymer to the respective chromophores. While, the side-chain and main-chain polymer systems, the former enhances material stability while the later extends the chromophore loading density. Advances in crosslinked EO polymers amended the molecular assembly of the chromophores, simultaneously increases the loading density of the chromophore and stability of the material. For the future applications, engineering of new EO polymeric materials, introducing novel device concepts, and high-precision instrument processing will benefit the EO polymers with excellent performance which will be demanded for future application in the optical field. Moreover, ease of synthetic routes, optimization, and reproducibility of the materials in economical means will be considered.

\section{Abbreviations}

NLO: Nonlinear optical; $r_{33}$ : Electro-optic coefficient; EO: Electro-optic; GHz: Gigahertz; $T_{g}$ : Glass transition temperature; $\mathrm{T}_{\mathrm{d}}$ : Decomposition temperature; SPH: Silicon-polymer hybrid; MZ: Mach-zehnder; D-A: Diels-Alder

\section{Acknowledgements}

Not applicable.

\section{Authors' contributions}

These authors contributed equally: Fateh Ullah, Niping Deng. Writing-original draft preparation: Fateh Ullah; organized chemical structures, added the conclusion and corrected the references, Niping Deng. All authors read and approved the final manuscript.

\section{Funding}

This work is supported by National Natural Science Foundation of China (62075184).

\section{Availability of data and materials}

Data sharing is not applicable to this article as no new data were created or analyzed in this study.

\section{Declaration}

\section{Competing interests}

The authors declare that they have no competing interests.

Received: 12 May 2021 Accepted: 18 June 2021

Published online: 28 July 2021

\section{References}

1. Benea-Chelmus I-C, Salamin Y, Settembrini FF, Fedoryshyn Y, Heni W, Elder DL, et al. Electro-optic interface for ultrasensitive intracavity electric field measurements at microwave and terahertz frequencies. Optica. 2020;7(5). https:// doi.org/10.1364/optica.384160.

2. Spring AM, Qiu F, Hong J, Bannaron A, Cheng X, Yokoyama S. Adamantyl and carbazole containing trans-poly (norbornene-dicarboximide) s as electro-optic chromophore hosts. Polymer. 2019;172:382-90. https://doi.org/10.1016/j. polymer.2019.04.015.

3. $\mathrm{Ma} \mathrm{H}, \mathrm{Wu}$ J, Herguth $\mathrm{P}$, Chen B, Jen AK. A novel class of high-performance perfluorocyclobutane-containing polymers for second-order nonlinear optics. Chem Mater. 2000;12(5):1187-9. https://doi.org/10.1021/cm000073h.

4. Brambilla G. Optical fibre nanowires and microwires: a review. J Optics-UK. 2010;12(4):043001. https://doi.org/10.1088/2 040-8978/12/4/043001.

5. Westbrook PS, Kremp T, Feder KS, Taunay TF, Monberg EM, Wu H, et al. Multicore optical fiber grating arrays for sensing applications. Ecoc Eur Conf Opt Commun. 2016;35(6):1248-52. https://doi.org/10.1109/JLT.2017.2661680.

6. Luo J, Jen AK. Highly efficient organic electrooptic materials and their hybrid systems for advanced photonic devices. IEEE J Sel Top Quant. 2013:19(6):42-53. https://doi.org/10.1109/jstqe.2013.2268385.

7. Oh MC, Zhang H, Zhang C, Erlig H, Chang Y, Tsap B, et al. Recent advances in electrooptic polymer modulators incorporating highly nonlinear chromophore. IEEE J Sel Top Quant. 2001;7(5):826-35. https://doi.org/10.1109/2944. 979344.

8. Shi Z, Luo J, Huang S, Polishak BM, Zhou XH, Liff S, et al. Achieving excellent electro-optic activity and thermal stability in poled polymers through an expeditious crosslinking process. J Mater Chem C. 2012;22(3):951-9. https://doi.org/10.103 9/C1JM14254B.

9. Dalton LR, Sullivan PA, Bale DH. Electric field poled organic electro-optic materials: state of the art and future prospects. Chem Rev. 2010;110(1):25-55. https://doi.org/10.1021/cr9000429.

10. Liu JL, Xu GM, Liu FG, Kityk I, Liua XH, Zhen Z. Recent advances in polymer electro-optic modulators. RSC Adv. 2015; 5(21):15784-94. https://doi.org/10.1039/c4ra13250e.

11. Ding R, Baehr-Jones T, Kim W, Spott A, Fournier M, Fedeli J, et al. Sub-volt silicon-organic electro-optic modulator with 500 mhz bandwidth. J Lightwave Technol. 2011;29(8):1112-7. https://doi.org/10.1109/jlt.2011.2122244. 
12. Dalton LR. Theory-inspired development of organic electro-optic materials. Thin Solid Films. 2009;518(2):428-31. https:// doi.org/10.1016/j.tsf.2009.07.001.

13. Shi Z, Hau S, Luo J, Kim TD, Jen KY. Highly efficient diels-alder crosslinkable electro-optic dendrimers for electric-field sensors. Adv Funct Mater. 2007;17(14):2557-63. https://doi.org/10.1002/adfm.200600778.

14. Benight SJ, Bale DH, Olbricht BC, Dalton LR. Organic electro-optics: Understanding material structure/function relationships and device fabrication issues. J Mater Chem. 2009;19(40). https://doi.org/10.1039/b905368a.

15. Taylor EW, Nichter JE, Nash FD, Haas F, Szep AA, Michalak RJ, et al. Radiation resistance of electro-optic polymer-based modulators. Appl Phys Lett. 2005;86(20):3335. https://doi.org/10.1063/1.1927713.

16. Liu J, Ouyang C, Huo F, He W, Cao A. Progress in the enhancement of electro-optic coefficients and orientation stability for organic second-order nonlinear optical materials. Dyes Pigments. 2020;181:108509. https://doi.org/10.1016/j.dyepig.2 020.108509 .

17. Wu JY, Li ZA, Luo JD, Jen AK. High-performance organic second- and third-order nonlinear optical materials for ultrafast information processing. J Mater Chem C C. 2020;8(43):15009-26. https://doi.org/10.1039/d0tc03224g.

18. Han XY, Wu ZL, Yang SC, Shen FF, Liang YX, Wang LH, et al. Recent progress of imprinted polymer photonic waveguide devices and applications. Polymers-Basel. 2018;10(6). https://doi.org/10.3390/polymer10060603.

19. Hu C, Chen Z, Xiao H, Zhen Z, Liu X, Bo S. Synthesis and characterization of a novel indoline based nonlinear optical chromophore with excellent electro-optic activity and high thermal stability by modifying the $\pi$-conjugated bridges. J Mater Chem C C. 2017;5(21):5111-8. https://doi.org/10.1039/c7tc00735c.

20. Yang $Y, X u H$, Liu F, Wang H, Deng G, Si P, et al. Synthesis and optical nonlinear property of y-type chromophores based on double-donor structures with excellent electro-optic activity. J Mater Chem C C. 2014;2(26):5124-32. https:// doi.org/10.1039/c4tc00508b.

21. Lei J, Guo C, Liu F, Chen S, Shi WJ, Wang Z, et al. Enhancement of electro-optic properties of nonlinear optical chromophores by introducing pentafluorobenzene group into the donor and $\pi$-bridge. Dyes Pigments. 2019;170: 107607. https://doi.org/10.1016/j.dyepig.2019.107607.

22. Cheng Z, Tang R, Wang R, Xie Y, Chen P, Liu G, et al. Photo-crosslinkable second-order nonlinear optical polymer: facile synthesis and enhanced nlo thermostability. Polym Chem. 2018;9(25):3522-7. https://doi.org/10.1039/c8py00686e.

23. Salamin Y, Benea-Chelmus IC, Fedoryshyn Y, Heni W, Elder DL, Dalton LR, et al. Compact and ultra-efficient broadband plasmonic terahertz field detector. Nat Commun. 2019;10(1):5550. https://doi.org/10.1038/s41467-019-13490-x.

24. Haffner C, Chelladurai D, Fedoryshyn Y, Josten A, Baeuerle B, Heni W, et al. Low-loss plasmon-assisted electro-optic modulator. Nature. 2018;556(7702):483-6. https://doi.org/10.1038/s41586-018-0031-4.

25. Salamin Y, Benea-Chelmus IC, Fedoryshyn Y, Heni W, Leuthold J. Compact and ultra-efficient broadband plasmonic terahertz field detector. Nat Commun. 2019;10(1):5550. https://doi.org/10.1038/s41467-019-13490-x.

26. Rau I, Puntus L, Kajzar F. Recent advances with electro-optic polymers. Mol Cryst Liq Cryst. 2019;694(1):73-116. https:// doi.org/10.1080/15421406.2020.1723898.

27. Wu J, Peng C, Xiao H, Bo S, Qiu L, Zhen Z, et al. Donor modification of nonlinear optical chromophores: synthesis, characterization, and fine-tuning of chromophores' mobility and steric hindrance to achieve ultra large electro-optic coefficients in guest-host electro-optic materials. Dyes Pigments. 2014;104:15-23. https://doi.org/10.1016/j.dyepig.2 013.12.023.

28. Liu F, Xiao H, Yang Y, Wang $\mathrm{H}$, Zhang $\mathrm{H}$, Liu J, et al. The design of nonlinear optical chromophores exhibiting large electro-optic activity and high thermal stability: the role of donor groups. Dyes Pigments. 2016;130:138-47. https:/doi. org/10.1016/.jdyepig.2016.03.003.

29. Huo F, Zhang H, Chen Z, Qiu L, Liu J, Bo S, et al. Novel nonlinear optical push-pull fluorene dyes chromophore as promising materials for telecommunications. J Mater Sci-Mater El. 2019;30(13):12180-5. https://doi.org/10.1007/s10854019-01576-7.

30. Stähelin M, Walsh CA, Burland DM, Miller RD, Twieg RJ, Volksen W. Orientational decay in poled second-order nonlinear optical guest-host polymers: temperature dependence and effects of poling geometry. J Appl Phys. 1993;73(12):8471-9. https://doi.org/10.1063/1.353421.

31. Yu F, Spring AM, Li L, Qiu F, Yamamoto K, Maeda D, et al. An enhanced host-guest electro-optical polymer system using poly (norbornene-dicarboximides) via ROMP. Polym Chem. 2013;51(6):1278-84. https://doi.org/10.1 002/pola.26505.

32. Deng G, Bo S, Zhou T, Zhang R, Liu J, Liu X, et al. Hydrogen-bonded network: an effective approach to improve the thermal stability of organic/polymer electro-optic materials. Sci China Chem. 2013;56(2):169-73. https://doi.org/10.1007/ s11426-012-4799-z.

33. Ouyang C, Liu J, Liu Q, Li Y, Yan D, Wang Q, et al. Preparation of main-chain polymers based on novel monomers with $d-\pi-a$ structure for application in organic second-order nonlinear optical materials with good long-term stability. ACS Appl Materr Inter. 2017;9(12):10366-70. https://doi.org/10.1021/acsami.7b00742.

34. Xu C, Wu B, Dalton LR, Ranon PM, Shi Y, Steier WH. New random main-chain, second-order nonlinear optical polymers, Macromolecules. 1992;25(24):6716-8. https://doi.org/10.1021/ma00050a052.

35. Pan J, Chen M, Warner W, He M, Dalton L, Hogen-Esch TE. Synthesis of block copolymers containing a main chain polymeric nlo segment. Macromolecules. 2000;33(13):4673-81. https://doi.org/10.1021/ma9921201.

36. Lin HL, Juang TY, Chan LH, Lee RH, Dai SA, Liu YL, et al. Sequential self-repetitive reaction toward wholly aromatic polyimides with highly stable optical nonlinearity. Polym Chem. 2011;2(3):685-93. https://doi.org/10.1039/c0py00157k.

37. Song MY, Jeon B, Lee JY. Synthesis and properties of novel nonlinear optical polyurethane containing dicyanovinylnitroresorcinoxy group. Mol Cryst Liq Cryst. 2013;581(1):83-8. https://doi.org/10.1080/15421406.2013.808557.

38. Gubbelmans E, Verbiest T, Van Beylen M, Persoons A, Samyn C. Chromophore-functionalised polymides with highpoling stabilities of the nonlinear optical effect at elevated temperature. Polymer. 2002;43(5):1581-5. https://doi.org/10.1 016/50032-3861(01)00678-4.

39. Chen TA, Jen AK, Cai Y. Two-step synthesis of side-chain aromatic polyimides for second-order nonlinear optics. Macromolecules. 1996;29(2):535-9. https://doi.org/10.1021/ma9512566.

40. Yu D, Gharavi A, Yu L. A generic approach to functionalizing aromatic polyimides for second-order nonlinear optics. Macromolecules. 1995;28(3):784-6. https://doi.org/10.1021/ma00107a017. 
41. Samyn C, Van den Broeck K, Verbiest T, Persoons A. (1999) synthesis and nonlinear optical properties of high glass transition polyimides and poly (maleimide-styrene)s. organic thin films for photonic applications. Santa Clara: Optical Society of America; 1999. https://doi.org/10.1002/(SICI)1521-3935(19991201)200:12<2629::AID-MACP2629>3.0.CO;2-K

42. Van den Broeck K, Verbiest T, Van Beylen M, Persoons A, Samyn C. Synthesis and nonlinear optical properties of high glass transition polyimides. Macromol Chem Phys. 1999;200(12):2629-35 https://doi.org/10.1002/(SICI)1521-3935(199912 01)200:12<2629::AID-MACP2629>3.0.CO;2-K.

43. Van den Broeck K, Verbiest T, Degryse J, Van Beylen M, Persoons A, Samyn C. High glass transition chromophore functionalised polyimides for second-order nonlinear optical applications. Polymer. 2001;42(8):3315-22. https://doi.org/1 0.1016/50032-3861(00)00761-8.

44. Qin A, Yang Z, Bai F, Ye C. Design and synthesis of a thermally stable second-order nonlinear optical chromophore and its poled polymers. Polym Chem. 2003;41(18):2846-53. https://doi.org/10.1002/pola.10871.

45. Tsai HC, Kuo WJ, Hsiue GH. Highly thermal stable main-chain nonlinear optical polyimide based on two-dimensional carbazole chromophores. Macromol Rapid Comm. 2005;26(12):986-91. https://doi.org/10.1002/marc.200500111.

46. Deng G, Bo S, Zhou T, Huang H, Wu J, Liu J, et al. Facile synthesis and electro-optic activities of new polycarbonates containing tricyanofuran-based nonlinear optical chromophores. Macromol Rapid Comm. 2013;51(13):2841-9. https:// doi.org/10.1002/pola.26673.

47. Singer KD, Kuzyk MG, Holland WR, Sohn JE, Lalama SJ, Comizzoli RB, et al. Electro-optic phase modulation and optical second-harmonic generation in corona-poled polymer films. Appl Phys Lett. 1988;53(19):1800-2. https://doi.org/10.1 063/1.99785.

48. Luo J, Haller M, Li HX, Kim TD, Jen AK. Highly efficient and thermally stable electro-optic polymer from a smartly controlled crosslinking process. Adv Mater. 2003;15(19):1635-8. https://doi.org/10.1002/adma.200305202.

49. Saadeh H, Wang L, Yu L. A new synthetic approach to novel polymers exhibiting large electrooptic coefficients and high thermal stability. Macromolecules. 2000;33(5):1570-6. https://doi.org/10.1021/ma991097g.

50. Jen AK, Wu X, Ma H. High-performance polyquinolines with pendent high-temperature chromophores for second-order nonlinear optics. Chem Mater. 1998;10(2):471-3. https://doi.org/10.1021/cm970739g.

51. Chen TA, Jen AK, Cai Y. A novel class of nonlinear optical side-chain polymer: Polyquinolines with large second-order nonlinearity and thermal stability. Chem Mater. 1996;8(3):607-9. https://doi.org/10.1021/cm9505916.

52. Lee ES, Kim SM, Yi MH, Ka JW, Oh MC. Coplanar electrode polymer modulators incorporating fluorinated polyimide backbone electro-optic polymer. Photonics-Basel. 2020;7(4):100. https://doi.org/10.3390/photonics7040100.

53. Tsutsumi N, Matsumoto O, Sakai W, Kiyotsukuri T. Nonlinear optical polymers. 2. Novel nlo linear polyurethane with dipole moments aligned transverse to the main backbone. Macromolecules. 1996;29(2):592-7. https://doi.org/10.1021/ ma9510770.

54. Tsutsumi N, Morishima M, Sakai W. Nonlinear optical (NLO) polymers. 3. Nlo polyimide with dipole moments aligned transverse to the imide linkage. Macromolecules. 1998;31(22):7764-9. https://doi.org/10.1021/ma9803436.

55. Tirelli N, Altomare A, Solaro R, Ciardelli F, Follonier S, Bosshard C, et al. Structure-activity relationship of new nlo organic materials based on push-pull azodyes: 4. Side chain polymers. Polymer. 2000;41(2):415-21. https://doi.org/10.1016/ S0032-3861(99)00202-5.

56. Luh TY, Chen RM, Hwu TY, Basu S, Shiau CW, Lin WY, et al. Rational design of polymers for optoelectronic interests pure and applied chemistry. Pure Appl Chem. 2001;73(2):243-6. https://doi.org/10.1351/pac200173020243.

57. Campbell D, Dix LR, Rostron P. Synthesis of poly vinyl ethers with pendant non-linear optical azo dyes. Eur Polym J. 1993;29(2):249-53. https://doi.org/10.1016/0014-3057(93)90091-S.

58. Ye C, Marks TJ, Yang J, Wong GK. Synthesis of molecular arrays with nonlinear optical properties: second-harmonic generation by covalently functionalized glassy polymers. Macromolecules. 1987;20(9):2322-4. https://doi.org/10.1021/ma $00175 \mathrm{a} 051$.

59. Hayden LM, Sauter GF, Ore FR, Pasillas PL, Hoover JM, Lindsay GA, et al. Second-order nonlinear optical measurements in guest-host and side-chain polymers. J Appl Phys. 1990;68(2):456-65. https://doi.org/10.1063/1.346815.

60. Moon KJ, Shim HK, Lee KS, Zieba J, Prasad PN. Synthesis, characterization, and second-order optical nonlinearity of a polyurethane structure functionalized with a hemicyanine dye. Macromolecules. 1996;29(3):861-7. https://doi.org/10.1 021/ma950275c.

61. Noël C, Gangadhara CKC, Large M, Reyx D, Kajzar F. Synthesis and characterization of polymers containing 4cyanobiphenyl-based side groups for nonlinear optical applications, 3. Poly(p-chloromethylstyrene) derivatives Macromol Chem Phys. 1997;198(5):1665-78. https://doi.org/10.1002/macp.1997.021980526.

62. Eckl M, Müller H, Strohriegl P, Beckmann S, Etzbach KH, Eich M, et al. Nonlinear optically active polymethacrylates with high glass transition temperatures. Macromol Chem Phys. 1995;196(1):315-25. https://doi.org/10.1002/macp.1995.021 960122.

63. Strohriegl P, Mueller $\mathrm{H}$, Nuyken O. Novel method for the preparation of polymethacrylates with nonlinear optically active side groups; 1993. https://doi.org/10.1117/12.139171.

64. Faccini M, Balakrishnan M, Torosantucci R, Driessen A, Reinhoudt DN, Verboom W. Facile attachment of nonlinear optical chromophores to polycarbonates. Macromolecules. 2008;41(22):8320-3. https://doi.org/10.1021/ma801875w.

65. Guo L, Guo Z, Li X. Design and preparation of side chain electro-optic polymeric materials based on novel organic second order nonlinear optical chromophores with double carboxyl groups. J Mater Sci-Mater El. 2018;29(3):2577-84. https://doi.org/10.1007/s10854-017-8181-y.

66. Miura H, Qiu F, Spring AM, Kashino T, Kikuchi T, Ozawa M, et al. High thermal stability 40 ghz electro-optic polymer modulators. Opt Express. 2017;25(23):28643-9. https://doi.org/10.1364/OE.25.028643.

67. Lu GW, Hong J, Qiu F, Spring AM, Kashino T, Oshima J, et al. High-temperature-resistant silicon-polymer hybrid modulator operating at up to $200 \mathrm{gbit} \mathrm{s}^{-1}$ for energy-efficient datacentres and harsh-environment applications. Nat Commun. 2020;11(1):4224. https://doi.org/10.1038/s41467-020-18005-7.

68. Tian Y, He Y, Liu P, Zhang H, Zheng Q, Liu J, et al. Mild and in situ photo-crosslinking of anthracene-functionalized poly (aryl ether ketone) for enhancing temporal stability of organic NLO materials. J Mater Sci. 2021;56(9):5910-23. https:// doi.org/10.1007/s10853-020-05594-3. 
69. McElhanon JR, Wheeler DR. Thermally responsive dendrons and dendrimers based on reversible furan-maleimide diels -alder adducts. Org Lett. 2001;3(17):2681-3. https://doi.org/10.1021/ol0101281.

70. Gheneim R, Perez-Berumen C, Gandini A. Diels-alder reactions with novel polymeric dienes and dienophiles: synthesis of reversibly cross-linked elastomers. Macromolecules. 2002;35(19):7246-53. https://doi.org/10.1021/ma020343c.

71. Liu J, Wang L, Zhen Z, Liu X. Synthesis of novel polyarylate with elecrooptical chromophores as side chain as electrooptic host polymer. Colloid Polym Sci. 2012;290(12):1215-20. https://doi.org/10.1007/s00396-012-2695-x.

72. Kim TD, Luo J, Tian Y, Ka JW, Tucker NM, Haller M, et al. Diels-alder "click chemistry" for highly efficient electrooptic polymers. Macromolecules. 2006;39(5):1676-80. https://doi.org/10.1021/ma052087k.

73. Shi Z, Cui YZ, Huang S, Li Z, Luo J, Jen AK. Dipolar chromophore facilitated huisgen cross-linking reactions for highly efficient and thermally stable electrooptic polymers. ACS Macro Lett. 2012;1(7):793-6. https://doi.org/10.1021/mz300 $89 \mathrm{p}$.

74. Cabanetos C, Bentoumi W, Silvestre V, Blart E, Pellegrin Y, Montembault V, et al. New cross-linkable polymers with huisgen reaction incorporating high $\mu \beta$ chromophores for second-order nonlinear optical applications. Chem Mater. 2012;24(6):1143-57. https://doi.org/10.1021/cm203590t.

75. Chen Z, Bo S, Qiu L, Zhen Z, Liu X. Synthesis and optical properties of a crosslinkable polymer system containing tricyanofuran-based chromophores with excellent electro-optic activity and thermal stability. Polym Int. 2012;61(9):137681. https://doi.org/10.1002/pi.4216

76. Zhang C, Wang C, Yang J, Dalton LR, Sun G, Zhang H, et al. Electric poling and relaxation of thermoset polyurethane second-order nonlinear optical materials: role of cross-linking and monomer rigidity. Macromolecules. 2001;34(2):235-43. https://doi.org/10.1021/ma0011688.

\section{Publisher's Note}

Springer Nature remains neutral with regard to jurisdictional claims in published maps and institutional affiliations.

\section{Submit your manuscript to a SpringerOpen ${ }^{\circ}$} journal and benefit from:

- Convenient online submission

- Rigorous peer review

- Open access: articles freely available online

High visibility within the field

- Retaining the copyright to your article 